REYISTA

dete

CEPA

NUMERO 62

AGOSTO 1997

SANTIAGO DE CHILE

OSCAR ALTIMIR

Direcsor

EUGENIO LAHERA

Secretario Técnico

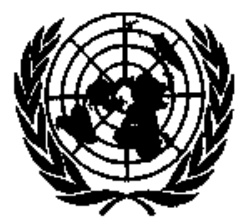

NACIONES UNIDAS 
Estado, comunidad y sociedad en el desarrollo social

Fermando Henrique Cardoso

Un balance de las reformas estructurales neoliberales en América Latina

Joseph Ramos

Deuda y sostenibilidad ffscal: ise repite la historia?

Guillermo E. Perry

Reformas petroleras: las opciones en juego

Fernando Sánchez Albavera

Las organizaciones indígenas: actores emergentes en

América Latina

Rodolfo Stavenhagen

El empleo rural no agropecuario en el Istmo Centroamericano

Jürgen Weller

Marginalidad e integración social en Uruguay

Rubén Kaztman

La política comercial en el marco de la Organización Mundial

de Comercio

Diana Tussie

Comercio y medio ambiente: ¿luz verde o luz roja?

Helga Hoffmann

Anclas nominales y escenarios de coordinación macroeconómica en el MERCoSUR

Gonzalo Rodríguez Prada

Políticas de promoción de exportaciones en Centroamérica

Larry Willmore

Publicaciones recientes de la CEPAL 


\section{Reformas petroleras: las opciones en juego}

\section{Fernando Sánchez Albavera}

Asesor Regional Principat

en Mineria y Energia,

División de Medio Ambiente

y Desurrollo, CEPAL
En los años noventa un buen número de países de la región puso en marcha importantes modificaciones en sus regímenes petroleros tendientes a suprimir los monopolios públicos, promover mercados competitivos y propiciar un incremento de la inversión privada bajo nuevas formas de contratación. Esta reforma tuvo una significativa incidencia en los programas de estabilización económica, por cuanto se aplicaron correcciones de precios que contribuyeron a reducir las presiones fiscales, junto con efectuarse la reestructuración y saneamiento financiero de las empresas petroleras públicas. Atrás quedó el estatismo que inspiró las políticas públicas hasta la década de los ochenta. Sin embargo, la privatización es sólo una de las opciones en juego. Más interesantes son los crecientes procesos de internacionalización de las empresas petroleras públicas mediante la concertación de asociaciones estratégicas entre ellas y también con las grandes empresas petroleras de fuera de la región. En suma, este artículo analiza el paradigma que inspira las reformas y las interrogantes que surgen sobre su piena validez al contrastarlo con la realidad, destacando tres grandes opciones en juego dentro de América Latina: i) la promoción de asociaciones estratégicas e internacionalización de empresas públicas; ii) el papel preponderante del Estado y la promoción de la inversión privada, y iii) la privatización total de la industria. 
I

\section{Introducción}

En los últimos años ha habido importantes modificaciones en los regímenes petroleros de Argentina, Brasil, Bolivia, Colombia, Ecuador, Perú y Venezuela.

Las reformas han desregulado cuando la competencia es posible y han regulado cuando no lo es. Se busca además promover la inversión extranjera bajo nuevas modalidades de contratación, lo que no excluye una significativa presencia del Estado en los países con mayor dimensión petrolera (Brasil, México y Venezuela) e inclusive en algunos países predominantemente importadores - por ejemplo en Chile, a través de la Empresa Nacional del Petróleo (ENAP)-

Por el momento, sólo en Argentina y Perú el desarrollo de la industria petrolera está hegemónicamente en manos del capital privado, tras la privatización de Yacimientos Petrolíferos Fiscales (YPF) y PETROPERÚ. En Bolivia está en marcha la privatización de Yacimientos Petrolíferos Fiscales Bolivianos (YPFB) bajo la modalidad de capitalización, y en Ecuador se alienta la inversión privada pero se mantiene una importante participación del Estado (PETROECUAdor). En Brasil (PETRobras), Colombia (ECOPETROL) y Venezuela (PDVSA) se promueven asociaciones estratégicas entre las empresas estatales y los grandes operadores petroleros internacionales, mientras que sólo en México persiste el monopolio estatal, aunque se profundiza la internacionalización de PEMEX.

\section{II}

\section{Avance de las reformas}

En líneas generales, la secuencia de las reformas ha seguido el siguiente derrotero: corrección de precios, reestructuración y saneamiento financiero de las empresas públicas, organización de un mercado competitivo, promoción de la inversión privada y, por último, privatización (alternativa minoritaria por el momento). ${ }^{1}$

$\mathrm{El}$ avance ha sido variable. El proceso está todavía en marcha pero sin duda los mayores logros, hasta el momento, tienen que ver con la corrección de precios y el saneamiento de las empresas públicas en el marco de los procesos integrales de reforma económica.

\section{Ajustes de precios}

La corrección de los precios tuvo en un primer momento motivaciones fiscales y estuvo orientada a reducir las transferencias presupuestarias para cubrir los déficit de las empresas públicas; por lo tanto, en algunos

\footnotetext{
' Chile es un caso particular ya que inició su reforma en 1978 , siguiendo estos pasos pero sin concretar la privatización de la Empresa Nacional del Petróleo (ENAP), que controla todas las refinerías.
}

casos adquirió cierta gradualidad vinculada a tos propósitos de los programas de estabilización económica.

Las empresas fueron mejorando progresivamente su participación en los precios finales de los combustibles $y$, por lo general, en una segunda instancia se adoptaron políticas que tomaron como referencia los precios internacionales, aunque este patrón no se aplica plenamente en todos los países de la región si se considera como criterio básico el costo de oportunidad.

\section{Reestructuración y saneamiento financiero de las empresas públicas}

El saneamiento financiero de las empresas petroleras se ha visto favorecido - aunque no en todos los casos y dependiendo de cada una de las realidades nacionales- por factores como los siguientes: la reorientación de las políticas de precios, la menor transferencia de recursos de las empresas al fisco, la reestructuración de los pasivos y la refinanciación de la deuda externa.

Se ha propiciado la formación de conglomerados en la actividad empresarial del Estado y se busca mejorar la eficiencia operacional, separando los costos y márgenes de utilidad o pérdida en cada una de 
las "unidades de negocios" y racionalizando el gasto corriente, a fin de reducir los costos. En algunos casos se han cerrado ciertas unidades de bajo rendimiento o se han aplicado esquemas de descentralización para hacer más transparente el funcionamiento de las diversas "unidades de negocios".

\section{Instauración de mercados competitivos y pro- moción de la inversión privada}

El mercado petrolero tiene características especiales que conviene destacar. Se trata de un mercado con "abastecimiento multivial" propio de los bienes energéticos transables bajo pautas comerciales aceptadas mundialmente.

Desde comienzos de los años noventa se contrapusieron dos opciones dentro de América Latina. Una que asume el carácter multivial del abastecimiento y postula la supresión de los monopolios estatales con y sin privatización de la industria; y otra minoritaria que, considerando el carácter estratégico del petróleo, insiste en el mantenimiento de barreras a la inversión privada.

Esta última posición considera que si bien el petróleo es un producto transable, se trata de una fuente energética no renovable, de uso difundido, que incide en el comportamiento de múltiples actividades y usuarios con fuerte impacto macroeconómico y ambiental, y que está sujeta a una serie de factores geopolíticos que podrian afectar la soberanía y seguridad nacionales.

La posición contraria sostiene que en una economía libre no debería haber "barreras de entrada" para la explotación de los recursos (oferta libre de restricciones) o para satisfacer la demanda (libre acceso al abastecimiento). En este marco resultaría contraproducente que ofertantes o demandantes pretendieran influir unilateral o concertadamente en el mercado. En consecuencia, el petróleo debería ser mirado como cualquier bien transable, lo que implicaría dejar de lado su carácter estratégico.

Se aboga, por lo tanto, en favor de un.Estado regulador, se descarta un Estado empresario que excluya la inversión privada, y se propicia la eliminación de los monopolios, por considerarlos inconvenientes para el desarrollo de la industria, ya que limitan la captación de capitales extranjeros y la transferencia de tecnología.

En realidad, lo que todavía está en discusión es si el Estado debe seguir cumpliendo un papel empresarial hegemónico, orientación que justificó las estatizaciones que se acentuaron en los años sesenta y se- tenta y perduraron hasta los ochenta, determinando que el $85 \%$ de la industria petrolera de la región estuviera bajo el control de las empresas del Estado a comienzos de los noventa.

Se insiste además en que el estatismo afectó la asignación de recursos al privilegiar la fijación de precios internos por debajo del costo de oportunidad del abastecimiento; con esto generó un esquema de transferencia de rentas que no ponderó adecuadamente la rentabilidad de los capitales invertidos, desfinanciando a las empresas públicas y llevando a elevados niveles de endeudamiento externo.

La mayoría de los países de la región, salvo México, ha eliminado las barreras de entrada a la inversión privada en las diversas fases de la industria petrolera, privilegiando operaciones independientes o en asociación con empresas del Estado

Se han producido importantes avances con respecto al decenio anterior en to que se refiere a la entrada de capital privado en las actividades de explotación, refinación y comercialización, con diversas modalidades de contratación con el capital nacional y extranjero (Campodónico, 1996b).

La instauración de mercados competitivos ha significado básicamente la eliminación de las restricciones a la importación y, en general, de los monopolios públicos de comercio exterior, aunque éstos persisten todavía en algunos países de la región. Ello se acompaño, aunque no en todos los casos, de criterios de regulación basados en la generación de condiciones de competencia, lo que ha permitido estructurar políticas de precios libres.

\section{Privatización de empresas públicas}

La privatización de empresas públicas petroleras no es una tendencia generalizada en la región, pues sólo en Argentina, Bolivia y Perú está presente como opción estratégica para el desarrollo de la industria.

Yacimientos Petrolíferos Fiscales (YPF) no sólo fue la primera empresa pública petrolera del mundo —creada en 1921 - sino también la primera gran empresa estatal de la región que se privatizó. En 1993 se vendio el $45 \%$ de las acciones de yPF en bolsas internacionales y argentinas mientras que el $13 \%$ se otorgó a los trabajadores como aporte a los fondos de pensiones. El Estado nacional mantiene el 20\% de las acciones, las provincias el $11.3 \%$ y el personal de YPF el $10 \%$ restante.

Si bien la mayor parte de las acciones se hallan en manos de inversionistas privados, la dispersion es bastante grande, de modo que el Estado sigue pesan- 
do en las decisiones de la empresa. Además, el voto afirmativo del Estado es indispensable para la aprobación de fusiones, la adquisición de más del $50 \%$ de las acciones de YPF, la transferencia total de los derechos de exploración y explotación y la disolución de YPF.

El esquema de privatización petrolera del Perú es radicalmente diferente. Allí se optó por la venta de "unidades de negocios", obtenidas de la desintegración de PITRoperú. La Refinería de la Pampilla, la mayor del país, fue vendida a un consorcio liderado por REPSOL. e YPF, reteniendo el Estado el $40 \%$ de las acciones. La planla de lubricantes se vendió íntegramente a MoBiL OIL y los totes que explotaba PETROPERú están siendo adjudicados bajo contratos de licencia que suponen un pago por el valor de las reservas que contienen y una regalía por la explotación del yacimiento.

En Bolivia, la nueva ley de petróleo dio marcha a la privatización de YPFB, bajo el esquema contemplado en la Ley de Capitalización. Según este esquema el comprador deberá efectuar un aporte de capital que le permita controlar la "unidad de negocios" que le interesa. El saldo restante se distribuiría entre los trabajadores como aporte a los fondos de pensiones. Al momento de escribir este artículo se han capitalizado los principales lotes de producción de petróleo y el transporte por oleoductos, estando pendiente la capitalización de las refinerías.

\section{III}

\section{Cambios en los regímenes de contratación petrolera}

En la región existen diversas modalidades de contratación petrolera que han ido variando con el tiempo, según los propósitos de las políticas públicas y los cambios que ha experimentado el mercado mundial del petróleo. En estas formas de contratación, que surgieron con mayor vigor en los años setenta, lo común es que los inversionistas asuman el riesgo de exploración (Campodónico, 1996a).

Así, se suscribieron contratos de "prestación de servicios" o de "operaciones" que reemplazaron, por esos años, el régimen convencional de concesiones petroleras. El cambio fue sustantivo, ya que anteriormente los concesionarios tenían plazos y condiciones mucho más flexibles para poner en operación las eventuales reservas probadas, reteniendo además la propiedad del petróleo extraído.

El nuevo régimen, cuyo origen se encuentra en las nacionalizaciones del Medio Oriente, implicaba dar un servicio a la empresa petrolera estatal que era dueña del petróleo y que a cambio de esta prestación (riesgo exploratorio y gastos de explotación) retribuía al contratista en especie o mediante el pago en efectivo de una tarifa, vinculada a los precios internacionales.

Por esos años se pusieron también en vigencia contratos de "participación en la producción", relativamente similares a los anteriores, por los cuales el contratista continuaba asumiendo el riesgo exploratorio a cambio de una proporción de la producción que, se- gún el caso, podía ser vendida a la empresa estatal a precios internacionales o colocada en mercados externos.

Las políticas públicas insistieron en que el Estado, como soberano de los recursos, no sólo tenía derecho a una proporción de la producción, sino además a decidir sobre el destino de los crudos extraídos, para garantizar el abastecimiento del mercado interno o bien para orientarlo al mercado internacional, según sus intereses comerciales.

Estas modalidades de contratación se extendieron a varios países de la región (Argentina, Bolivia, Brasil, Chile, Ecuador, Perú) en los años setenta, coincidiendo con el fortalecimiento de la concertación petrolera oficial en el marco de la Organización de Países Exportadores de Petróleo (OPEP).

En medio de los efectos de la primera crisis del petróleo (a comienzos de los años setenta) y ante el temor de que se pusiera en riesgo el abastecimiento de los países importadores, los contratistas petroleros llegaron a concretar acuerdos que entregaron a las empresas estatales el $50 \%$ del petróleo extraído, e inclusive un poco más, sin que éstas asumieran riesgo alguno.

En Colombia, se adoptó un régimen diferente: el contratista asumía el riesgo exploratorio y si encontraba reservas comerciales debía asociarse obligatoriamente con la empresa ECOPETROL para la explotación del petróleo encontrado. 
Estos nuevos esquemas de contratación fueron auspiciados incluso por las grandes empresas petroleras, las que optaron por dar un servicio o asociarse con empresas estatales, considerando que el reparto de los beneficios de la negociación petrolera siempre fue un tema conflictivo que inspiró las políticas de intervención pública y las estatizaciones. Estas políticas se aplicaban hacía largo tiempo en algunos países de la región, pero se comenzaron a reforzar desde fines de los años sesenta, y adquirieron mayor vigor estimuladas por los nuevos enfoques que surgieron a raíz de la creación de la OPEP. ${ }^{2}$

Perú estatizó la industria petrolera en 1968, Ecuador en 1971 y Venezuela en 1975. Los años setenta marcan pues el inicio de un largo período en que los Estados de la región asumieron un mayor protagonismo en la actividad petrolera. Pero, con las excepciones de México y Venezuela, no excluyeron la participación privada bajo las nuevas reglas de contratación.

Estas reglas delimitaron las obligaciones de los contratistas, exigiendo programas de trabajo obligatorios en la fase de exploración; programas de desarrollo con compromisos específicos de inversión en la fase de explotación, y las correspondientes garantías bancarias que aseguraran el cumplimiento de estos compromisos.

En los años ochenta, y como resultado de la mayor oferta de crudo en el mercado mundial, se empezó a flexibilizar los niveles de retribución a los contratistas con el fin de atraer mayores inversiones, pero las pautas de contratación no se alteraron mayormente.

La apertura petrolera, en lo que va de los años noventa, ha significado la introducción de nuevas modalidades en el régimen de contratación. Estas tienen vigencia básjcamente en Argentina y Perú, con la reinstauración de la modalidad de concesión y con los "contratos de licencia" respectivamente, en los que, a cambio de una regalía, los contratistas tienen derecho a la propiedad del petróleo extraído.
Las novedades más importantes son, sin duda, la supresión del monopolio de pETrobras en Brasil en 1995 y los nuevos contratos para la explotación de campos marginales que suscribió Venezuela en 19921993, así como los recientes contratos de ganancias compartidas que dicho país empezó a suscribir a partir de 1996.

Considerando las reservas que están en juego, la política de apertura de Venezuela tendrá seguramente un impacto decisivo en el mercado mundial y en las pautas de concertación (cuotas de producción y exportación) dentro de la opep.

Cabe destacar que la modalidad de contratación sobre la base de ganancias compartidas resulta, sin duda, más atractiva en un país de las características de Venezuela. Su aplicación sería muy difícil en la mayoría de los países de la región cuyo riesgo exploratorio es significativamente mayor que en Venezuela.

Otra novedad interesante respecto al régimen de contratación es la introducción de criterios que vinculan la participación de los contratistas con la cantidad y calidad de petróleo extraído (Ecuador) y con los ingresos (Colombia). En el primer caso, a mayor cantidad de petróleo extraído menor participación del contratista, mientras que en el segundo un alza de precios le significaría una menor retribución porcentual.

En cuanto a tratamiento tributario y arancelario, destaca la uniformación de criterios con los regímenes comunes al resto de las actividades productivas, que guarda relación con la neutralidad de la tributación. En este sentido, la industria petrolera no tiene un tratamiento ni más ni menos favorable que el resto de las actividades productivas. Sin embargo, algunos países (Ecuador, Guatemala y Perú) mantienen todavía incentivos arancelarios para la fase de exploración.

Hay que destacar que las tasas del impuesto a la renta ban decrecido significativamente en algunos países, lo que ha significado un tratamiento más favorable que el prevaleciente en los años ochenta.

\section{IV}

\section{Del paradigma a la realidad}

\footnotetext{
${ }^{2}$ Argentina, como se señaló inás atrís, constituyó en 1921 la primera empresa petrolera estatal del mundo (YPF). En la década de los treinta se creó la Empresa Petrolera Fiscal (1934) en Perú e yper (1936) en Bolivia, mientras que México estatizo la industria en 1938 y formó PEMEX. En los años cincuenta se constituyó en Chile la ENAP (1950), ECOPETROL (195J) en Colombia y PETROBRAS (1953) en Brasil.
}

La búsqueda de competitividad y el menor protagonismo estatal son la base del paradigma que impulsa las reformas petroleras en la región, aunque las dosis de una y otro dependen de la dotación de reservas y de la naturaleza de los mercados nacionales. 
El paradigma plantea que la intervención estatal sólo tiene sentido si se presentan imperfecciones del mercado, y asigna al Estado un papel regulatorio orientado a garantizar una mayor competencia y a proteger el patrimonio natural. Las cuestiones de seguridad de abastecimiento o de equidad social significarían situacionss de excepción frente a las cuales entraría en vigor la subsidiariedad del Estado.

Sin embargo, algunos datos de la realidad ponen en tela de juicio los efectos de la aplicación del paradigma que orienta las reformas petroleras en los ámbitos que se indican a continuación.

\section{Concentración de la industria}

La primera interrogante surge frente al incremento de la concentración de la industria que resultaría de una masiva privatización la que pondría en tela de juicio el equilibrio entre productores y consumidores $y$, por ende, la vigencia de un mercado libre.

Las políticas públicas que se aplicaron a partir de los aiios setenta propiciaron la desconcentración de la industria petrolera mundial. En 1971, las llamadas "siets hermanas" controlaban el $58 \%$ de la oferta petrolera mundial, pero a mediados de los noventa daban cuenta solamente de $13 \%$ de la producción mundial (Gutiérrez y Jaramitlo, 1995).

Il poder económico que encierran las empresas petroleras es considerable y deriva no sólo de la magnitud de sus operaciones sino de la significativa proporción del comercio intrafirma que realizan. Baste mencionar que las operaciones anuales de las $52 \mathrm{em}$ presas petroleras que se encuentran entre las $600 \mathrm{em}$ presas más grandes del mundo alcanzan a alrededor de 800 mil millones de dólares. Esta cifra triplicó la de las exportaciones regionales de 1996 y la de los capitales extranjeros que ingresaron a la región entre 1990 y 1996 (Naciones Unidas, 1988; CEPAL, 1996).

lis difícil aventurar juicios respecto de los efectos que la mayor concentración de la industria tendría sobre el funcionamiento del mercado mundial. Lo que sí es svidente es que la privatización afectará la concertación de políticas entre los productores de los países en desarrollo (en la opep). Esta concertación sería contradictoria con el paradigma del libre mercado. Así, mientras la reforma implica un menor protagonismo público, la geopolítica aconseja un mayor pragmatismo

\footnotetext{
${ }^{3}$ Las siete hermanas son: British Petroleum, Standard Oil of New Jersey, Exxon, Royal Dutch Shell, Gulf, Standard Oil of Colifornia y Mobil Oil.
}

que no alteraría mayormente el importante papel que desempeña el Estado en la coordinación de tas políticas energéticas de los países desarrollados.

Los países europeos signatarios de la Carta Europea de la Energía reconocen que los Estados tienen derecho a participar en la prospección y explotación de los recursos energéticos mediante la participación del gobierno o de sus empresas estatales, admitiendo la posibilidad de expropiar por razones de interés público.

Por otro lado, los países miembros de la Agencia Internacional de la Energía han avanzado significativamente en la coordinación de sus políticas de planificación estratégica: han fijado topes máximos de importación, límites mínimos de almacenamiento y mecanismos para enfrentar crisis mundiales de abastecimiento de petróleo y productos refínados. Además, después de la Guerra del Golfo, los países de la Organización de Cooperación y Desarrollo Económicos (OCDE) están prestando cada vez más atención a la seguridad del suministro energético, y muchos de ellos (Francia, Bélgica e Italia entre otros) asignan carácter estratégico a sus empresas.

De allí que la eliminación de barreras a la entrada de inversión privada haya sido prudente y concebida más bien en términos de "asociaciones estratégicas" en los países que concentran la mayor parte de las reservas petroleras regionales (México y Venezuela), a fin de tener un mayor margen de maniobra para delinear iniciativas nacionales vinculadas al comportamiento del mercado mundial.

\section{Distribución de la renta petrolera}

La segunda interrogante tiene que ver con la distribución de los beneficios de la explotación de los recursos naturales, que estuvo en el eje de las motivaciones que inspiraron las políticas estatistas.

El uso de la renta petrolera en la región no fue el más adecuado. En algunos casos, se postergaron urgentes reformas tributarias que hubieran llevado a una "despetrolización" del gasto fiscal. En otros se distorsionaron los precios, reduciendo esa renta con fines antiinflacionarios, o se adoptó una política de succión de los ingresos de las empresas públicas, lo que las descapitalizó y afectó severamente sus gastos de inversión.

El terna es importante tanto bajo el protagonismo estatal como cuando se propicia la privatización de la industria. Por un lado, debería evitarse que el consumo fiscal de la renta petrolera perjudique el desarrollo 
de la industria; y por otro, la promoción de la inversión privada no debería desembocar en un deterioro de la renta media que se retiene en las economías nacionales.

Lo importante seria mantener un equilibrio sustentable en el reparto de los beneficios, de modo que los arreglos contractuales entre el Estado y los operadores privados tengan estabilidad en el largo plazo.

\section{Seguridad del abastecimiento y sus efectos sobre los precios}

Otra interrogante que surge en el marco de las reformas se refiere a la seguridad del abastecimiento y al comportamiento de los precios, asunto que es importante tanto para los países productores como para los países consumidores .

La seguridad del abastecimiento continuará siendo un tema crucial en la geopolítica mundial, si bien el petróleo reducirá su participación en la estructura del consumo de la energía primaria de cerca del $40 \%$ a comienzos de los noventa, al $37 \%$ al concluir el primer decenio del próximo siglo (Campodónico, 1996b).

En ese lapso, los países de la ocDE reducirían su participación en la demanda mundial de petróleo del 56 al $47 \%$ por la sustitución de fuentes energéticas y un uso más eficiente de la energía. Pero se volverán más dependientes aún del abastecimiento importado, porque la relación reservas/producción es hoy, en promedio, de ocho años en Europa occidental y de 1 I años en América del Norte. En América Latina, en cambio, la relación es de 50 años; de allí el interés porque América Latina aumente su participación en el abastecimiento de la ocoE (Campodónico, 1996b).

La puesta en producción de mayores reservas regionales - dada la incertidumbre política que persiste en el Medio Oriente y Rusia - haría más seguro el abastecimiento de petróleo a la vez que la mayor oferta regional contribuiría a reducir las presiones alcistas sobre las cotizaciones mundiales. Como los precios reales de hoy están deprimidos con respecto a los elevados precios de los setenta, los países exportadores de la región tendrán que hacer un esfuerzo productivo mayor para obtener los bienes que importan del mercado mundial. Por lo tanto, la gestión empresarial tendrá que centrarse en los costos para evitar que se reduzca la renta petrolera.

\section{Imperfecciones del mercado}

En la región, la mayoría de los países ha eliminado los controles al comercio exterior y ha realizado importan- tes reformas en la etapas de refinación y transporte del petróleo. Sólo en México y Venezuela existen barreras de entrada a estas actividades. En los demás países se admite la inversión privada en la refinación y los operadores privados pueden construir oleoductos bajo un esquema de libre acceso a las redes y regulación de tarifas; la comercialización en estaciones de servicio es libre y prácticamente no existen controles de precios.

La aplicación del paradigma no debería olvidar la posible existencia de monopolios naturales. Si bien algunas fases de la industria admiten la competencia, lo decisivo es la magnitud de los mercados. Por su variada dimensión, los mercados internos de los países de la región admitirían desde una vigencia plena de la competencia, hasta formas de oligopolio e inclusive monopolio, en el caso de los países más pequeกิos.

Esto lleva a una interrogante que tiene relación con el nivel de los precios internos (incluidos los impuestos) y su impacto en las cuentas macroeconómicas y la competitividad internacional.

Hay quienes consideran que los países productores podrían tener mayores márgenes de libertad en la fjjación de los precios internos del petróleo aun a riesgo de disminuir la rentabilidad de las empresas estatales, si se toma en cuenta el costo de oportunidad, a efectos de frenar las presiones inflacionarias o mejorar la competitividad.

Los países dependientes del abastecimiento importado simplemente no tienen alternativa más eficiente que la de fijar los precios internos en función de los internacionales. En todo caso, el nivel de impuestos debe manejarse con prudencia para no generar presiones inflacionarias ni afectar la competitividad de los usuarios.

\section{5. ¿Integración o desintegración de la industria?}

La historia de la industria petrolera muestra que la integración vertical fue y sigue siendo un imperativo para captar la diferencia entre la renta de explotación y el valor agregado por la refínación y la comercialización, lo que no se contrapone a la descentralización de la gestión.

Mantener o no la integración de la industria ha sido tema de debate al plantearse la opción privatizadora. Poner en venta varias "unidades de negocios" puede ser aconsejable en mercados de gran dimensión, pero puede perjudicar la competencia en mercados pequeños si se constituyen monopolios en 
cada fase de la industria. En este caso, como cuando se cambia un monopolio integrado público por uno privado, la posibilidad de desregulación es más limitada.

\section{La situación de la actividad petrolera en los años noventa}

Los países con mayores reservas tienen serias dudas sobre la plena validez del paradigma en boga, considerando la importancia que tiene el petróleo en sus relaciones internacionales. Sin embargo, la concertación de las políticas de precios (en la OPEP) ha perdido vigor, no sólo por la mayor injerencia privada sino también porque los países con mayores reservas en la región no desean involucrarse en opciones multilaterales que reduzcan sus márgenes de libertad. ${ }^{4}$

El debilitamiento de la concertación es un costo derivado del claro interés por atraer más inversión privada. Este objetivo podría tener también cierto impacto fiscal -asunto que está todavía por evaluarsesi las nuevas condiciones de contratación implican que el Estado traspase el control de la renta petrolera a cambio de regalías e impuestos a la renta.

Sólo los países con una amplia y probada filiación petrolera pueden lograr beneficios más equilibrados y hasta imponer condiciones de negociación. En cambio, los que han visto disminuir sus reservas bajo el predominio estatal y presentan altos riesgos de exploración, se inclinan de manera realista por regímenes de contratación más flexibles y atractivos.

El nivel de reservas disponibles y la evolución positiva que se espera para la oferta ponen a los consumidores en mejores condiciones de negociación, lo que no significa que el petróleo deje de ser un producto crucial en la geopolítica mundial.

L.o importante es que los países de la región, en el marco de la reforma, puedan conciliar los objetivos de autoabastecimiento o de incremento de su participación en el mercado mundial, atraer mayores corrientes de inversión y retener una proporción creciente del valor de producción (a través de compras internas, salarios, impuestos, regalías, etc.), ya que no se debe

\footnotetext{
${ }^{4}$ Ecuador se salio de la oper, México nunca formó parte de ella y Venezusla tha tratado de ampliar su cuota dentro de esta organiza* ción.
}

considerar sólo los beneficios que capta el fisco, sino el efecto integral en las economías nacionales.

El tema de la renta petrolera es sin duda de extremada importancia. En los países exportadores interesa montar mecanismos regulatorios y tributarios que permitan que los precios declarados por los operadores correspondan efectivamente a las mejores opciones de colocación en el mercado internacional, evitando que posibles estrategias de comercio administrado lleven a la fijación de precios de transferencia que perjudiquen el valor de las exportaciones y por ende los ingresos tributarios. Los países importadores, por otro lado, requieren de mecanismos regulatorios para acceder a las mejores condiciones de precio y evitar que las posiciones dominantes en el mercado resulten en ineficiencias en el abastecimiento.

En ambos casos el patrón de referencia debería ser el precio internacional del tipo de producto requerido, con lo cual tanto las operaciones de las empresas petroleras como la recaudación tributaria han de corresponder efectivamente al costo de oportunidad.

Los países de la región deberán crear, teniendo en cuenta sus potencialidades nacionales, un mecanismo institucional con capacidad de contratación (para la exploración y explotación), capacidad de tiscalización (supervisión de contratos, tributación y captación de renta) y capacidad regulatoria para garantizar que el mercado opere en situaciones competitivas. No está de más advertir que en estos tres campos las deficiencias de muchos países de la región son todavfa significativas.

La privatización de las empresas petroleras públicas es una alternativa, pero no es la única ni puede decirse que sea compartida por la mayoría de los países de la región. En lo que sí hay un consenso claro e irreductible es en la necesidad de promover la inversión privada bajo las formas de contratación o de asociación que aconsejen las realidades nacionales (Campodónico, 1996c). 
Sobre el futuro desarrollo de la industria petrole$\mathrm{ra}$, al momento de escribir este artículo están en juego tres opciones que se describen a continuación.

\section{Promoción de "asociaciones estratégicas" e internacionalización de las empresas públicas}

Esta opción, que predomina en Chile, Brasil, México y Venezuela, con las diferencias y variantes del caso, admite varias posibilidades, que van desde la incursión en operaciones en países distintos al país sede de la empresa estatal para satisfacer las necesidades de abastecimiento interno de petróleo (Chile y Brasil), pasando por contratos de operaciones o de participación en la producción, hasta llegar a la concertación de diversas "asociaciones estratégicas" para ampliar y fortalecer tecnologicamente la exploración y explotación de petróleo.

En Brasil, la reforma constitucional suprimió el monopolio de PETROBRAS y abrió a operadores privados la posibilidad de intervenir en todas las fases de la industria. La privatización fue descartada, atendiendo a la significación de PETROBRAS en la economía nacional. ${ }^{5}$

Las operaciones internacionales de PETROBRAS se realizan a través de BRASPETRO, obteniendo ingresos brutos de 1428 millones de dólares y una utilidad neta de 39 millones de dólares. Abarcan actividades de exploración, desarrollo, producción de petróleo y prestación de servicios en Africa (Angola y Libia), América del Sur (Argentina, Ecuador y Colombia), Estados Unidos y el Reino Unido, en el Mar del Norte (PETROBRAS, 1995).

En el caso de PEMEX de México, la predisposición a concertar alianzas estratégicas se manifjesta, por ejemplo, en la adquisición del $3.5 \%$ de REPSOL de España; y la creación de una sociedad de proyectos, coinversión y contratos de suministro de petróleo que le abrió nuevas perspectivas comerciales dentro de la Unión Europea. A lo anterior se suma la constitución

\footnotetext{
${ }^{5}$ Las operaciones de petrobras equivalen a cerca de $2 \%$ del pis de Brasil. Si se agregan sus operaciones como conglomerado y la compra de bienes y servicios internos, esa participación podrá llegar hasta A 25\%: El conglomerado mismo genera 50000 empleos y se estima que tos efectos de sus operaciones significan 1.5 millones de puestos de trabajo. El patrimonio de PETrobras es superior a los 50000 millones de dólares (Mendes Renno, 1994). Se estima que desde su oreación el ahorro de divisas debido al aumento de la capacidad de réfinación fue de 223800 millones de dólares, y que en sus 40 affos de actividades ba invertido unos 88000 millones. En 1995 et conglomerado pagó en impuestos 6516 millones de dólates (PEtrobras, 1995).
}

de MEXPETROL, en asociación con capitales privados, para exportar servicios y productos en proyectos de operaciones petroleras y en la industria petroquímica (Arpel, 1990, pp. 86 y 87).

En 1992, PEMEX concretó además una asociación estratégica con SHELL para ampliar su capacidad de refinación, adquiriendo el $50 \%$ de una refinería en Texas (Deer Park, con capacidad de 220 mil barriles diarios).

La internacionalización de Povsa de Venezuela avanza con más rapidez que la de PEMEX. Desde principios de los años ochenta esta empresa buscó asegurarse mercados para sus excedentes exportables de petróleo, a la vez que ampliaba su integración vertical para incrementar el valor agregado, exportando productos refinados y adquiriendo refinerías en el extranjero. Esta política de internacionalización le permitió concretar asociaciones estratégicas con UNOVEN y UNOCAL en los Estados Unidos, con Ruhr Oel Gmbh de Alemania y con AB Nynas Petroleum de Suecia (Campodónico, 1996c).

Dentro de esta estrategia de internacionalización se inscribe la promoción de la inversión privada en la industria petrolera venezolana. PDVSA contempla para el periodo 1997-2006 inversiones por unos $60 \mathrm{mil}$ millones de dólares: $55 \%$ de PDVSA, $18 \%$ a través de asociaciones, y el $27 \%$ restante concertado con empresas privadas, bajo contratos de operaciones. De este total se han concretado inversiones por unos $33 \mathrm{mil}$ millones de dólares: cerca de 4 mil millones corresponden a la suscripción de contratos de operaciones para campos marginales; 10 mil millones a contratos de ganancias compartidas; 14 mil millones a asociaciones estratégicas en la faja del Orinoco y unos 5 mil millones al Proyecto de Gas Cristobal Colón (PDVSA, 1996).

Las estrategias de internacionalización de las empresas estatales también consideran asociaciones estratégicas con empresas públicas y privadas de la región. Casos ilustrativos son los convenios de la empresa estatal chilena ENAP con empresas argentinas (BRIDAS e YPF); los acuerdos entre PETROBRAS e YPF y el proyecto de PDVSA Y PETROBRAS para formar PETROAMÉRICA; $y$ el interés de MARAVEN, subsidiaria de PDVSA, por operar en los mercados de Colombia, Ecuador y Perú (Campodónico, 1996c).

En Chile, la enmienda constitucional de 1980 autorizó la participación privada mediante concesiones y contratos de "participación a riesgo", ${ }^{6}$ descartándo-

6 En estos contratos el contratista asume todo el riesgo de exploración. 
se la privatización de ENAP. La empresa fue reestructuradia en 1981: se formaron dos sociedades (PETROX y Refinería de Concón) encargadas de manejar las refinerías como subsidiarias de la ENAP.

Como los resultados de las exploraciones no fueron interesantes y el déficit de abastecimiento interno fue creciendo, se promovió la búsqueda de petróleo en el exterior mediante la creación de SIPETROL. En una primera etapa se dio prioridad a las operaciones en la región; se concretaron acuerdos en Argentina, Ecuador y Venezuela, y se estudiaron prospectos petroleros en países fuera de la región (Campodónico, 1996c).

\section{Papel preponderante del Estado y promoción de la inversión privada}

Esta es una opción intermedia entre la que apunta a formar asociaciones estratégicas e internacionalizar las empresas públicas, y la que es exclusivamente privatizadoria.

En la opción intermedia el desarrollo de la industria se sustenta en el mantenimiento de una empresa estatal que negocia diversas modalidades de participación en la producción, dejando que el riesgo exploratorio sea asumido por los inversionistas privados, lo que no excluye la incursión estrictamente privada en diversas fases de la industria.

Puede considerarse que esta opción ha sido la de Colombia, donde predomina un esquema de asociación obligatoria con ECOPETROL. Ecuador ha privilegiado los contratos de "participación a riesgo"; la privatización de PETROECUADOR no está por el momento en la orden del día por diferentes circunstancias, entre las que puede mencionarse su significacion fiscal y la participación de algunas entidades nacionales (como las fuerzas armadas) en la distribución de la renta petrolera.

\section{Privatización total de la Industria}

Esta opción está en juego en Argentina, Bolivia y Perú, con variantes en la modalidad de privatización. Argentina y Perú, como se vio anteriormente, privatizaron de diferente manera sus empresas estatales. El mantenimiento de la integración vertical de YPF tiene la virtud de sustentar un creciente proceso de internacionalización. YPF ha planeado afectuar el $15 \%$ de sus gastos de exploración fuera de Argentina, con miras a satisfacer las necesidades de petróleo de este país; proyecta actividades exploratorias en varios países de la región (Bolivia y Perú) y en el Golfo de México.

Por otro lado, su estrategia de internacionalización contempla acuerdos con importantes operadores internacionales (Campodónico, 1996c), como la asociación con British Petroleum, Amoco y maxus (empresa esta última en la que adquirió el $25 \%$ del capital en 1996) para la exploración en Venezuela; las relaciones con British Gas para evaluar el potencial de zonas aledañas a las Islas Malvinas, y su asociación con REPSOL de España y MOBiL orl de Estados Unidos en la privatización de la principal refinería de petróleo del Perú (la Refinería de La Pampilla).

Con la adquisición del $25 \%$ de maxus, ypF podrá proyectarse fuera de la región (a Estados Unidos e Indonesia), beneficiándose de tecnología para operaciones costa afuera y de las participaciones que maxus tiene en Bolivia, Ecuador y Venezuela. Su proyección dentro de la region se ve reforzada por sus asociaciones con empresas públicas y por su dinámica incursión en la comercialización interna de combustibles, en Brasil, Chile y Perú (Campodónico, 1996c).

La experiencia de yPF deberá ser observada con atención en el futuro ya que presenta particularidades que podrían ser de interés para otros países en desarrollo dentro y fuera de là región. La estrategia de privatización que adoptó esta empresa se basó en el mantenimiento del grado de integración vertical; la adopción de un esquema de "acciones doradas" (con poder de veto) para la participación estatal, y la apertura a las bolsas internacionales del paquete accionario en venta para interesar a inversionistas institucionales. Cabe precisar también que la operación bursátil de YPF fue una de las más importantes de este siglo en lo que toca a la incursión de países de la región en los mercados internacionales de capitales.

Lo interesante de esta modalidád de privatización es que no priva al Estado de influir en el curso futuro de la empresa, sirio que lo hace participar en una creciente internacionalización derivada de una nueva estrategia empresarial en la que tiene parte activa el Estado; si se hubiera optado por vender la mayoría de las acciones a un gran operador internacional, la industria petrolera argentina estaría subordinada a la estrategia de ese operador. Este proceso, desde el punto de vista nacional, se ve reforzado además por la activa participación de empresas privadas argentinas (BRIDAS, PLUSPETROL y otras) en la exploración y explotación de campos petroleros en varios países de la región.

El caso peruano es muy diferente. No se mantuvo la integración de la empresa, fragmentándose PETROPERÚ en varias "unidades de negocios" dentro del proceso de privatización. El mercado peruano está ahora en manos de grandes operadores internaciona- 
les (MOBIL, REPSOL) y de YPF de Argentina, que han establecido diversas relaciones de propiedad entre sí. Aunque es temprano todavía para evaluar la experiencia peruana, parece tenderse a una reintegración de la industria, que dada la dimensión del mercado interno, po- ne en tela de juicio el nivel efectivo de competencia.

La experiencia peruana, al igual que la de YPF, servirá a otros países de la región en los que el paradigma en boga está siendo aplicado casi a plenitud. En Bolivia el proceso de privatización está todavía en marcha, por lo que es prematuro sacar conclusiones.

\section{VI}

\section{Criterios de evaluación}

Por último, conviene precisar cuáles serían los criterios para evaluar los resultados de las tres alternativas que están en juego en la región. Lo que interesaría ante todo es determinar qué proporción de la renta petrolera se mantiene bajo el control del Estado en cada una de las opciones en juego.

La renta petrolera surge de la diferencia entre los costos de producción y el precio internacional, que se determina no sólo por la oferta y la demanda sino por factores ajenos al mercado. Este margen es apreciable en la mayoría de los países productores de la región, aun a los bajos precios actuales.

No parecería suficiente, por lo tanto, comparar el nivel de utilidades que tendrían las empresas privatizadas con las pérdidas que sufrían las empresas esta- tales, por cuanto estas últimas por lo general se vieron impedidas de fijar sus precios a los niveles internacionales. Si hubieran disfrutado de esta facultad que ahora determina los precios de las empresas privadas, sí sería válido utilizar tal criterio. En consecuencia, sería preferible considerar como criterio de evaluación las mejoras de eficiencia derivadas de la reducción de costos, por cuanto se trata de una industria que "toma" los precios internacionales. Queda pendiente para un análisis posterior la forma en que estas mejoras de eficiencia por el mayor margen entre costos y precios podrían trasladarse a los consumidores, teniendo en cuenta que la reforma apunta a que los precios de venta internos correspondan a los precios internacionales.

\section{Bibliografia}

ARPEL (Asistencia Recíproca Petrolera Empresarial Latinoamericana) (1990): Libro de plata, Buenos Aires, septiembre.

Campodónico, H. (1996a): Cambios en el régimen de contratación petrolera en América Latina en la década de los noventa. LC/R.1626, Santiago de Chile, Comisión Econónica para América Latina y el Caribe (CEPAL), División de Medio Ambiente y Desarrollo, marzo.

(1996b): Tendencias del mercado petrolero mundial y sus implicancias en la inversión extranjera de La industria petrolera de los paíser de América Latina y el Caribe, LC/R 1628, Santiago de Chile, CEPAL, División de Medio Ambiente y Desarrollo, marzo.

(1996c): El ajuste petrolero: políticas empresariales en América Latina de cara al 2000 , Lima, Centro de Estudios y Promoción del Desarrollo (DESCO), diciembre.

CEPAL (1996): Balance preliminar de la ecomomía de América Latina y el Caribe, 1996. LC/G.1947-P, Santiago de Chile, diciem- bre. Publicación de las Naciones Unidas, $\mathrm{N}^{*}$ de venta S.96.II.G.I3.

Gutiértez, F. y C. Jaramillo (1995): La modernización y privatización del subsector petrolero latinoamericano, Quito, Organización Latinoamericana de Energía (OLADE), junio.

Mendes Renno, J. (1994): Exposición de Joel Mendes Renno, Presidente de PETROBRAS, en la Universidad Federal de Rio de Janeiro, Cuadernos de Energía, No 1, Rio de Janeiro, Universi. dad Federal do Rio de Janeiro, marzo.

Naciones Unidas (1988); Las empresas trancnacionales en el desarrollo mundial: tendencias y perspectivas. Nueva Yotk, Publicación de las Naciones Unidas, $\mathrm{N}^{\circ}$ de venta 88.II.A.7.

PDVSA (Petróleos de Venezuela, S.A.) (1996): Plan de negocios 1997-2006, Caracas.

PETrobras (Petroleo Brasileiro) (1995): Memoria Anual, Rio de Janeiro. 1995. 